\title{
Sparking Creativity with the Game Boy Advance
}

\author{
Wouter Groeneveld \\ KU Leuven \\ Leuven, Belgium \\ wouter.groeneveld@kuleuven.be
}

\author{
Kris Aerts \\ KU Leuven \\ Leuven, Belgium \\ kris.aerts@kuleuven.be
}

\begin{abstract}
Numerous studies have shown that Game-Based Learning positively impacts educational effectiveness and student motivation. However, according to Amabile's Componential Model of Creativity [2], motivation is only one aspect of creativity, next to expertise and creative skills. Therefore, we looked beyond motivational aspects in order to amplify all dimensions of creativity. In a 'Software Design in C++' course at our local faculty of Engineering Technology, students learn to apply high-level object-oriented software development techniques on low-level embedded hardware. By introducing the Game Boy Advance (GBA), a 32-bit handheld released by Nintendo in 2001, students not only need the domain-specific technical expertise and motivation to succeed, but also the right creative skills to cope with the limitations of this embedded system that has only $96 \mathrm{~kb}$ of VRAM. We focused the labs on stimulating these creative problem-solving techniques. Results are promising: students were highly motivated and creative output was distinctly increased; but technical expertise was still lacking during examination. Further work involves investigating the impact of peerassessment on all aspects of creativity.
\end{abstract}

\section{CCS CONCEPTS}

- Applied computing $\rightarrow$ Education; $\bullet$ Social and professional topics $\rightarrow$ Student assessment;

\section{KEYWORDS}

Nintendo Game Boy, GBA, C++, software design, student motivation, creativity, peer-assessment

\section{INTRODUCTION / BACKGROUND}

While completely reworking the 'Software Design in C++' course previous academic year, we focused on real-life, embedded system experiences to trigger the creative skills of students. In total, between 30 and 35 students are enrolled each year in this obligatory module. As previous studies have shown [3, 4], the introduction of the Game Boy Advance is a great way to trigger the interest of students. In context of the Componential Model [2], we wondered: how can we stimulate all dimensions of student creativity, within the limits of a programming course?

Permission to make digital or hard copies of part or all of this work for personal or classroom use is granted without fee provided that copies are not made or distributed for profit or commercial advantage and that copies bear this notice and the full citation on the first page. Copyrights for third-party components of this work must be honored.

For all other uses, contact the owner/author(s).

SIGCSE '20, March 11-14, 2020, Portland, OR, USA

(C) 2020 Copyright held by the owner/author(s).

ACM ISBN 978-1-4503-6793-6/20/03

https://doi.org/10.1145/3328778.3372606

\section{OVERVIEW / METHODS / RESULTS}

Besides the teaching of technical expertise, we also focused our exercises on stimulating creative skills. For example, working with constraints (e.g. splitting sprites to conserve memory space) is very important in a limited environment such as the GBA. To minimize technical frustrations, we built an object-oriented sprite engine that students can use in their project. The engine ${ }^{1}$ hides low-level plumbing code in favor of readable high-level methods.

During the first year after reworking the course, we collected initial feedback from 24 students using a short survey. Only $4 \%$ of the students admitted not to be motivated. Main motivators were doing something else than working with normal micro-controllers (1), being able to make a game on the GBA (2), the ability to play it on actual hardware (3), immediate graphical feedback (4), creativity of assignment due to freedom (5), uniqueness (6), nostalgia (7). Main demotivators were unfamiliarity with tools (1), debugging (2), high initial difficulty (3), too ambitious projects (4).

We used Amabile's Consensual Assessment Technique [1] to evaluate the creativity of the end product. Instructors rated each game on different criteria, each with their own weight: design (0.5), clean code (0.5), usage of conventions ( 0.1$)$, complexity (0.3), originality $(0.3)$, UI $(0.2)$. This covers both the technical and creative skills dimensions of creativity.

In addition to the survey, we asked students to record their time spent on the project. In the next years, we will introduce a peerevaluation system that enables students to assess the creativity of others. We expect the implicit peer pressure to be a clear improvement in the quality of their assignment.

\section{CONTRIBUTIONS AND FUTURE WORK}

A compilation of the results of the survey and a video showcasing the work of students is available at https://brainbaking.com/ teaching/cpp/en/. We plan to update this for future academic years.

By emphasizing all dimensions of creativity instead of only technical expertise, we hope to inspire educators to also think about these aspects when designing and evaluating a Computing course. We will be further looking into other ways to explicitly teach and assess creative skills, instead of only relying on the end result.

\section{REFERENCES}

[1] Teresa M Amabile. 1982. Social psychology of creativity: A consensual assessment technique. Fournal of personality and social psychology 43, 5 (1982), 997.

[2] Teresa M Amabile. 1988. A model of creativity and innovation in organizations. Research in organizational behavior 10, 1 (1988), 123-167.

[3] Ian Finlayson. 2017. Using the Game Boy Advance to teach computer systems and architecture. Fournal of Computing Sciences in Colleges 32, 3 (2017), 78-84.

[4] Marina Papastergiou. 2009. Digital Game-Based Learning in high school Computer Science education: Impact on educational effectiveness and student motivation. Computers and Education 52, 1 (2009), 1-12. https://doi.org/10.1016/j. compedu.2008.06.004

$\overline{{ }^{1} \text { Available at https://github.com/wgroeneveld/gba-sprite-engine/. }}$ 